\title{
Natural Gas Dehydration
}

\author{
Michal Netušil and Pavel Ditl
}

Additional information is available at the end of the chapter

http://dx.doi.org/10.5772/45802

\section{Introduction}

The theme of natural gas (NG) dehydration is closely linked with storage of natural gas. There are two basic reasons why NG storage is important. Firstly, it can reduce dependency on NG supply. With this in mind, national strategic reserves are created. Secondly, NG storage enables the maximum capacity of distribution lines to be exploited. NG is stored in summer periods, when there is lower demand for it, and is withdrawn in the winter periods, when significant amounts of NG are used for heating. Reserves smooth seasonal peaks and also short-term peaks of NG consumption. Underground Gas Storages (UGS) are the most advantageous option for storing large volumes of gas. Nowadays there are approximately 135 UGSs inside the European Union. Their total maximum technical storage capacity is around $10^{9} \mathrm{~ms}^{3}$. According to the latest update, over $0,7 \cdot 10^{9} \mathrm{~ms}^{3}$ of additional storage capacity will come on stream in Europe by 2020 [1]. There are three types of UGSs: (1) Aquifers, (2) Depleted oil/gas fields, and (3) Cavern reservoirs (salt or hard rock). Each of these types possesses distinct physical characteristics. The important parameters describing the appropriateness of UGS use are storage capacity, maximum injection/withdrawal performance, and gas contamination during storage. Generally, the allowable pressure of stored gas inside a UGS is up to $20 \mathrm{MPa}$. The pressure inside increases as the gas is being injected, and decreases when gas is withdrawn. The output gas pressure depends on further distribution. Distribution sites from UGS normally begin at $7 \mathrm{MPa}$. The temperature of the gas usually ranges from $20-35^{\circ} \mathrm{C}$. The exact temperature varies with the location of the UGS and with the time of year.

\subsection{Water in the gas}

A disadvantage of UGSs is that during storage the gas become saturated by water vapors. In the case of depleted oil field UGSs, vapors of higher hydrocarbons also contaminate the stored gas. The directive for gas distribution sets the allowable concentration of water and concentration of higher hydrocarbons. In the US and Canada, the amount of allowable water 
in the gas is specified in units: pounds of water vapor per million cubic feet (lbs/MMcft). This amount should be lower than $7 \mathrm{lbs} / \mathrm{MMcft}$ [2], which is equivalent to $0,112 \mathrm{gH}_{\mathrm{H}} / \mathrm{ms}^{3}$. In Europe, the concentration of water and higher hydrocarbons is specified by their dew point temperature (Tdew). Tdew for water is $-7^{\circ} \mathrm{C}$ for $\mathrm{NG}$ at $4 \mathrm{MPa}$, and $\mathrm{T}_{\text {dew }}$ for hydrocarbons is $0^{\circ} \mathrm{C}$ for NG at the operating pressures [3]. This value for water is equivalent to roughly 0,131 $\mathrm{gH} 2 \mathrm{O} / \mathrm{ms}^{3}$ of $\mathrm{NG}$ at $4 \mathrm{MPa}$. As was stated above, the distribution specifications depend on the geographic region in which they are applied. For example, in Nigeria water $T_{\text {dew }}$ should be below $4^{\circ} \mathrm{C}$ for $\mathrm{NG}$ at $4 \mathrm{MPa}$, which means that the NG can contain more than twice as much water vapors as in Europe.

The water content of NG at saturation is dependent on temperature and pressure. With increasing pressure of the gas the water content decreases, and with increasing temperature the water content in the gas increases. This is well presented in Figure No. 20, Chapter 20, in the GPSA Data Book, $12^{\text {th }}$ Edition. The water content of the gas can be calculated using the following equation $[4,5]$ :

$$
w_{\text {water }}=593,335 \cdot \exp \left(0.05486 \cdot t_{G}\right) \cdot P_{G}{ }^{-0.81462}
$$

Where wwater is in kilograms of water per $10^{6} \mathrm{~ms}^{3}$ of NG, tG is temperature of NG in ${ }^{\circ} \mathrm{C}$, and $\mathrm{PG}_{\mathrm{G}}$ is pressure of $\mathrm{NG}$ in $\mathrm{MPa}$.

The average value of water in NG withdrawn from UGS is 2 - 5 times higher than required. An NG dehydration step is therefore essential before further distribution.

\subsection{Problems with water in the gas}

If the temperature of pipeline walls or storage tanks decreases below the $\mathrm{T}_{\mathrm{dew}}$ of the water vapors present in the gas, the water starts to condense on those cold surfaces, and the following problems can appear.

- $\quad$ NG in combination with liquid water can form methane hydrate. Methane hydrate is a solid in which a large amount of methane is trapped within the crystal structure of water, forming a solid similar to ice. The methane hydrate production from a unit amount of water is higher than the ice formation. The methane hydrates formed by cooling may plug the valves, the fittings or even pipelines.

- $\quad \mathrm{NG}$ dissolved in condensed water is corrosive, especially when it contains $\mathrm{CO}_{2}$ or $\mathrm{H}_{2} \mathrm{~S}$.

- Condensed water in the pipeline causes slug flow and erosion.

- Water vapor increases the volume and decreases the heating value of the gas.

- NG with the presence of water vapor cannot be operated on cryogenic plants.

\section{Dehydration methods}

\subsection{Absorption}

The most widely-used method for industrial dehydration of NG is absorption. Absorption is usually performed using triethyleneglycol sorbent (TEG). Absorption proceeds at low 
temperatures and the absorbed water is boiled out from TEG during regeneration in a reboiler at high temperatures. Some physical properties of pure TEG are given in the following text.

Viscosity data vs. temperature is shown in Table 1 and is shown in a graph in Figure 1 [6].

\begin{tabular}{|l|l|l|l|l|l|l|l|l|l|l|l|l|}
\hline$\left[{ }^{\circ} \mathrm{C}\right]$ & 4 & 10 & 16 & 21 & 27 & 32 & 38 & 43 & 49 & 54 & 60 & 66 \\
\hline$\left[\mathrm{m}^{2} / \mathrm{s} 10^{-5}\right]$ & 9,53 & 7,094 & 5,367 & 4,124 & 3,214 & 2,539 & 2,032 & 1,646 & 1,348 & 1,116 & 0,934 & 0,788 \\
\hline$\left[{ }^{\circ} \mathrm{C}\right]$ & 71 & 77 & 82 & 88 & 93 & 99 & 104 & 110 & 116 & 121 & 127 & 132 \\
\hline$\left[\mathrm{m}^{2} / \mathrm{s} 10^{-5}\right]$ & 0,672 & 0,577 & 0,5 & 0,436 & 0,384 & 0,34 & 0,303 & 0,272 & 0,245 & 0,222 & 0,203 & 0,186 \\
\hline$\left[{ }^{\circ} \mathrm{C}\right]$ & 138 & 143 & 149 & 154 & 160 & 166 & 171 & 177 & 182 & 188 & 193 & 199 \\
\hline$\left[\mathrm{m}^{2} / \mathrm{s} 10^{-5}\right]$ & 0,171 & 0,159 & 0,147 & 0,138 & 0,129 & 0,121 & 0,115 & 0,109 & 0,103 & 0,099 & 0,095 & 0,091 \\
\hline
\end{tabular}

Table 1. Kinematic viscosity of TEG according to temperature

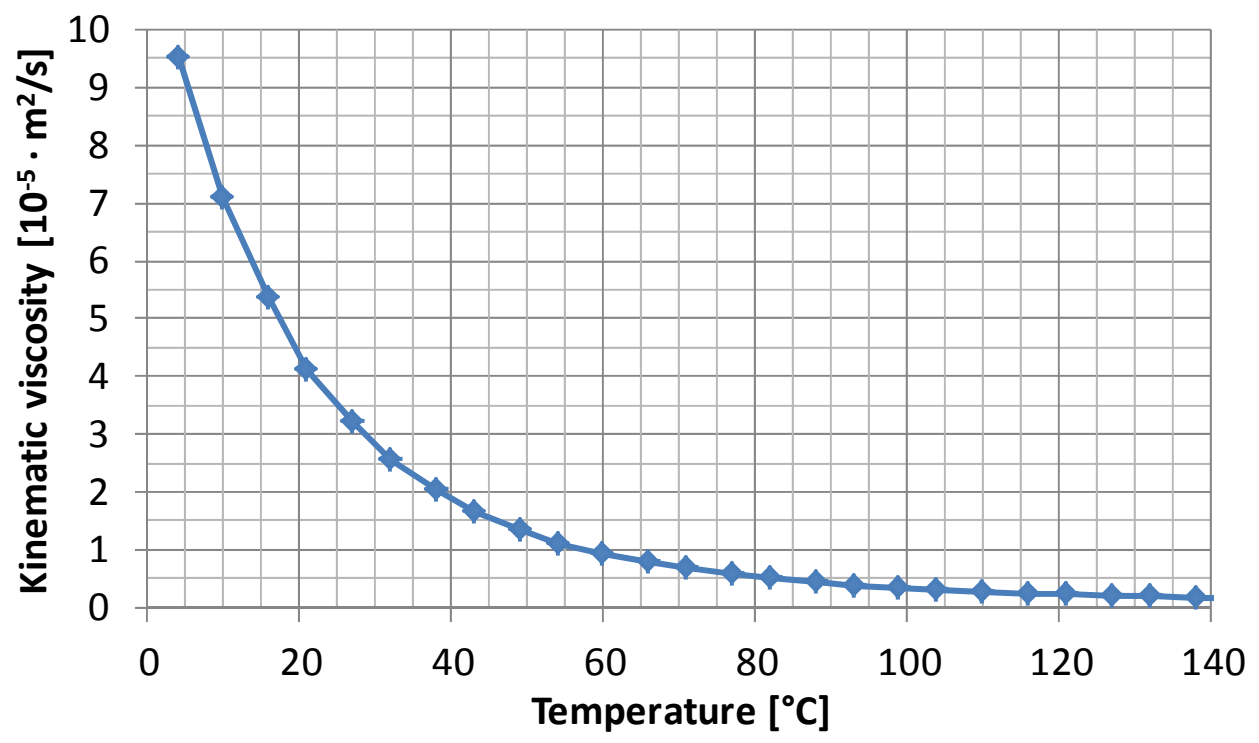

Figure 1. Kinematic viscosity of TEG as a function of temperature

It follows from Figure 1 that the kinematic viscosity of TEG increases dramatically with low temperatures. The temperature of TEG during a process should never decrease below $10^{\circ} \mathrm{C}$. The reason is to prevent pump damage or even clogging of the flow. For temperatures above $100^{\circ} \mathrm{C}$, the viscosity changes just slightly and the average kinetic viscosity value $5 \cdot 10^{-6}$ $\mathrm{m}^{2} / \mathrm{s}$ can be used. For a description of the dependency of viscosity on temperature, the following polynomial interpolation coefficients have been calculated.

$$
\begin{gathered}
v=1,159 \cdot 10^{-4}-5,655 \cdot 10^{-6} t+1,347 \cdot 10^{-7} t^{2}+1,872 \cdot 10^{-9} t^{3}+1,572 \cdot 10^{-11} t^{4} \\
-7,820 \cdot 10^{-14} t^{5}+2,116 \cdot 10^{-16} t^{6}-2,393 \cdot 10^{-19} t^{7}
\end{gathered}
$$


The density of TEG at various temperatures is shown in the following table [7].

\begin{tabular}{|l|l|l|l|l|l|l|l|l|l|l|l|l|l|}
\hline$\left[{ }^{\circ} \mathrm{C}\right]$ & 10 & 16 & 21 & 27 & 32 & 38 & 43 & 49 & 54 & 60 & 66 & 71 & 77 \\
\hline$\left[\mathrm{kg} / \mathrm{m}^{3}\right]$ & 1132 & 1128 & 1124 & 1119 & 1114 & 1111 & 1106 & 1101 & 1098 & 1093 & 1089 & 1084 & 1080 \\
\hline$\left[{ }^{\circ} \mathrm{C}\right]$ & 82 & 88 & 93 & 99 & 104 & 110 & 116 & 121 & 127 & 132 & 138 & 143 & 149 \\
\hline$\left[\mathrm{kg} / \mathrm{m}^{3}\right]$ & 1076 & 1071 & 1066 & 1063 & 1058 & 1053 & 1050 & 1045 & 1041 & 1036 & 1032 & 1028 & 1023 \\
\hline$\left[{ }^{\circ} \mathrm{C}\right]$ & 154 & 160 & 166 & 171 & 177 & 182 & 188 & 193 & 199 & 204 & 210 & 216 & 221 \\
\hline$\left[\mathrm{kg} / \mathrm{m}^{3}\right]$ & 1019 & 1015 & 1010 & 1007 & 1002 & 997 & 993 & 989 & 984 & 980 & 975 & 972 & 967 \\
\hline
\end{tabular}

Table 2. Density of TEG according to temperature

Table 2 shows that in the range of working temperatures the density of TEG is a linear function of temperature. The following equation can be used for determining the density at a certain temperature.

$$
\rho=-0,7831 \cdot t+1140
$$

Finally, the thermal conductivity of TEG does not change in the range of working temperatures and has a value of $0,194 \mathrm{~W} / \mathrm{m}^{2} /{ }^{\circ} \mathrm{C}$.

For determining the physical properties of TEG solutions with water (concentrations CTEG above $95 \mathrm{wt} . \%$ ), the activity coefficient of water in TEG can be approximated by the following equation.

$$
\gamma=-0,0585 \cdot c_{T E G}+6,2443
$$

The industrial absorption dehydration process proceeds in a glycol contactor (a tray column or packet bed). In a contactor, a countercurrent flow of wet NG and TEG is arranged. During the contact, the TEG is enriched by water and flows out of the bottom part of the contactor. The enriched TEG then continues into the internal heat exchanger, which is incorporated at the top of the still column in the regeneration section of the absorption unit. It then flows into the flash drum, where the flash gases are released and separated from the stream. The TEG then runs to the cold side of the TEG/TEG heat exchanger. Just afterwards, the warmed TEG is filtered and then runs into the regeneration section, where is it sprayed in the still column. From there, the TEG runs into the reboiler. In the reboiler, water is boiled out of the TEG. The regeneration energy is around $282 \mathrm{~kJ}$ per liter of TEG. The temperature inside should not exceed $208^{\circ} \mathrm{C}$, due to the decomposition temperature of TEG. Regenerated (lean) TEG is then pumped back through the hot side of the TEG/TEG and NG/TEG heat exchanger into the top of the contactor. The entire method is depicted in Figure 2 [8].

The circulation rate $\left(\mathrm{l}_{\mathrm{TEG}} / \mathrm{kgH}_{\mathrm{H}} \mathrm{O}\right)$ and the purity of the regenerated TEG are the main limiting factors determining the output $\mathrm{T}_{\mathrm{dew}}$ of NG. The amount of circulating TEG is around 40 times the amount of water to be removed. The minimal TEG concentration should be above 95 wt.\%, but the recommended value is higher. However, to obtain TEG concentration above 99 wt.\% enhanced TEG regeneration has to be implemented.

The simplest regeneration enhancing method is gas stripping. Proprietary designs DRIZO ${ }^{\circledR}$, licensed by Poser-NAT, and COLDFINGER ${ }^{\circledR}$, licensed by Gas Conditioners International, 


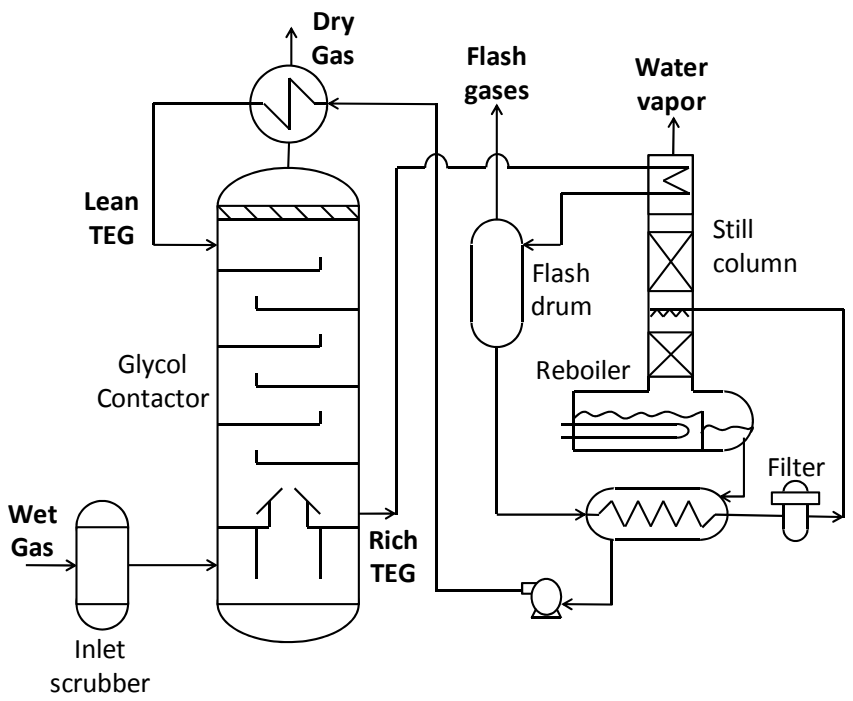

Figure 2. TEG absorption dehydration scheme

have been patented as an alternative to traditional stripping gas units. The Drizo regeneration system utilizes a recoverable solvent as the stripping medium. The patent operates with iso-octant solvent, but the typical composition of the stripping medium is about $60 \mathrm{wt} . \%$ aromatic hydrocarbons, $30 \mathrm{wt} . \%$ naphthenes and $10 \mathrm{wt} . \%$ paraffins. The three-phase solvent water separator is crucial for this method. The Coldfinger regeneration system employs a cooling coil (the "coldfinger") in the vapor space of the surge tank. The cooling that takes place there causes condensation of a high amount of vapors. The condensate is a water-rich TEG mixture, which is led to a further separation process [9]. Figure 3 depicts enhanced regeneration systems which replace the simple reboiler in the regeneration section shown in Figure 2.
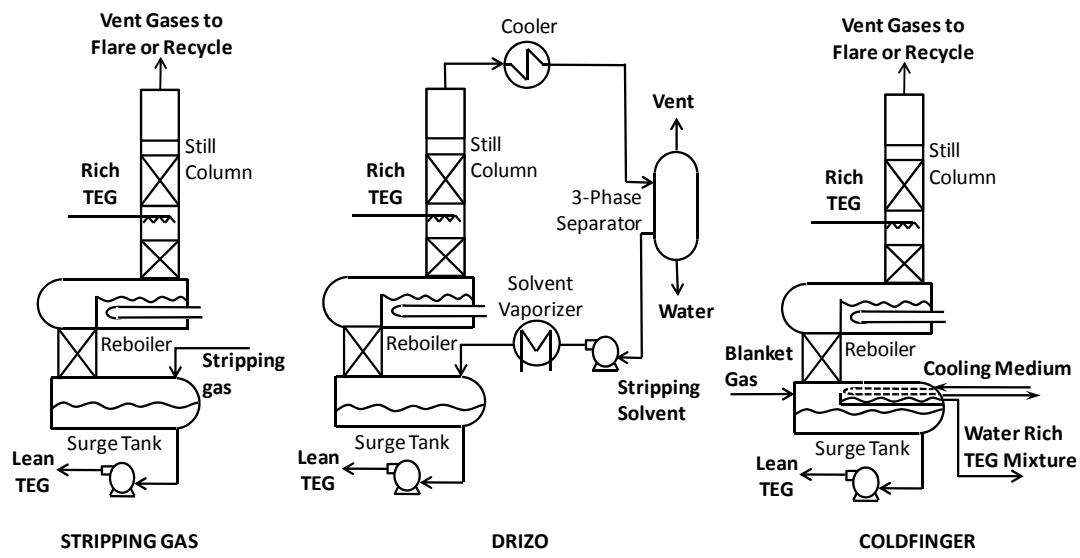

Figure 3. Enhanced TEG regeneration systems 


\subsection{Adsorption}

The second dehydration method is adsorption of water by a solid desiccant. In this method, water is usually adsorbed on a mole sieve, on a silica gel or on alumina. A comparison of the physical properties of each desiccant is shown in Table $3[4,10]$.

\begin{tabular}{|l|l|l|l|}
\hline Properties & Silica gel & Alumina & Mol. sieves \\
\hline Specific area $\left[\mathrm{m}^{2} / \mathrm{g}\right]$ & $750-830$ & 210 & $650-800$ \\
\hline Pore volume $\left[\mathrm{cm}^{3} / \mathrm{g}\right]$ & $0,4-0,45$ & 0,21 & 0,27 \\
\hline Pore diameter $[\AA]$ & 22 & 26 & $4-5$ \\
\hline Design capacity $[\mathrm{kg} \mathrm{H2O} / 100 \mathrm{~kg}$ desiccant] & $7-9$ & $4-7$ & $9-12$ \\
\hline Density $\left[\mathrm{kg} / \mathrm{m}^{3}\right]$ & 721 & $800-880$ & $690-720$ \\
\hline Heat capacity $\left[\mathrm{J} / \mathrm{kg} /{ }^{\circ} \mathrm{C}\right]$ & 920 & 240 & 200 \\
\hline Regeneration temperature $\left[{ }^{\circ} \mathrm{C}\right]$ & 230 & 240 & 290 \\
\hline Heat of desorption $[\mathrm{J}]$ & 3256 & 4183 & 3718 \\
\hline
\end{tabular}

Table 3. Comparison of the physical properties of desiccants used for dehydration of NG

The amount of adsorbed water molecules increases with the pressure of the gas and decreases with its temperature. These facts are taken into account when the process parameters are designed. Adsorption dehydration columns always work periodically. A minimum of two bed systems are used. Typically one bed dries the gas while the other is being regenerated. Regeneration is performed by preheated gas, or by part of the dehydrated NG, as depicted in Figure 4.

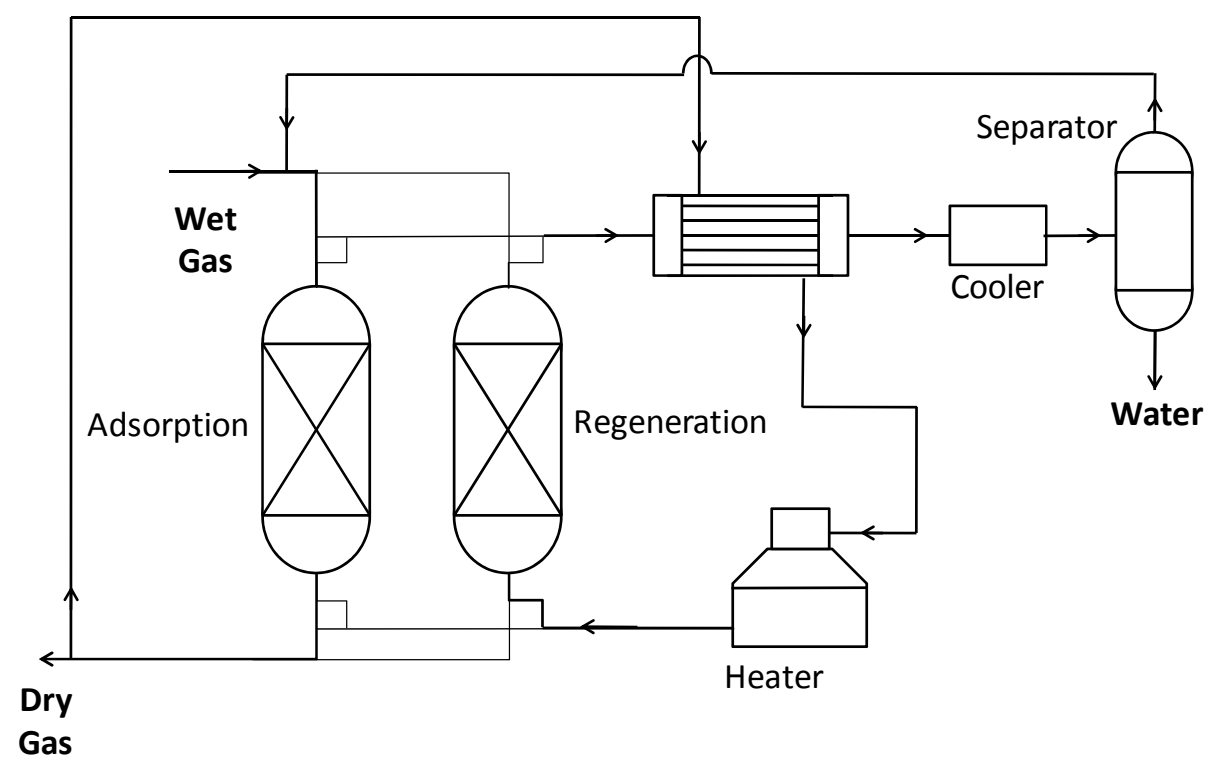

Figure 4. Scheme of the temperature swing adsorption dehydration process 
This method is known as temperature swing adsorption (TSA). Regeneration can also be performed by change of pressure - pressure swing adsorption (PSA). However, PSA is not industrially applied for NG dehydration. Further details about PSA can be found in [11,12]. A combination of those two methods (PSA and TSA) seems to be a promising future option for adsorption dehydration of NG. This idea is still in the research process.

In classical applications, the TSA heater is realized as an ordinary burner or as a shell and tube heat exchanger warmed by steam or by hot oil. The regeneration gas warms in the heater and flows into the column. In the column passes through the adsorbent and the water desorbs into the regeneration gas. The water saturated regeneration gas then flows into the cooler. The cooler usually uses cold air to decrease the temperature of the regeneration gas. When the water saturated regeneration gas is cooled, partial condensation of the water occurs. The regeneration gas is led further into the separator, where the condensed water is removed.

A downstream flow of wet NG through the adsorption column is usually applied. In this way, floating and channeling of an adsorbent is avoided. Regeneration is performed by countercurrent flow in order to provide complete regeneration from the bottom of the column, where the last contact of the dried NG with the adsorbent proceeds. The typical temperature course for $12 \mathrm{~h}$ regeneration of molecular sieves is shown in Figure 5 [13].

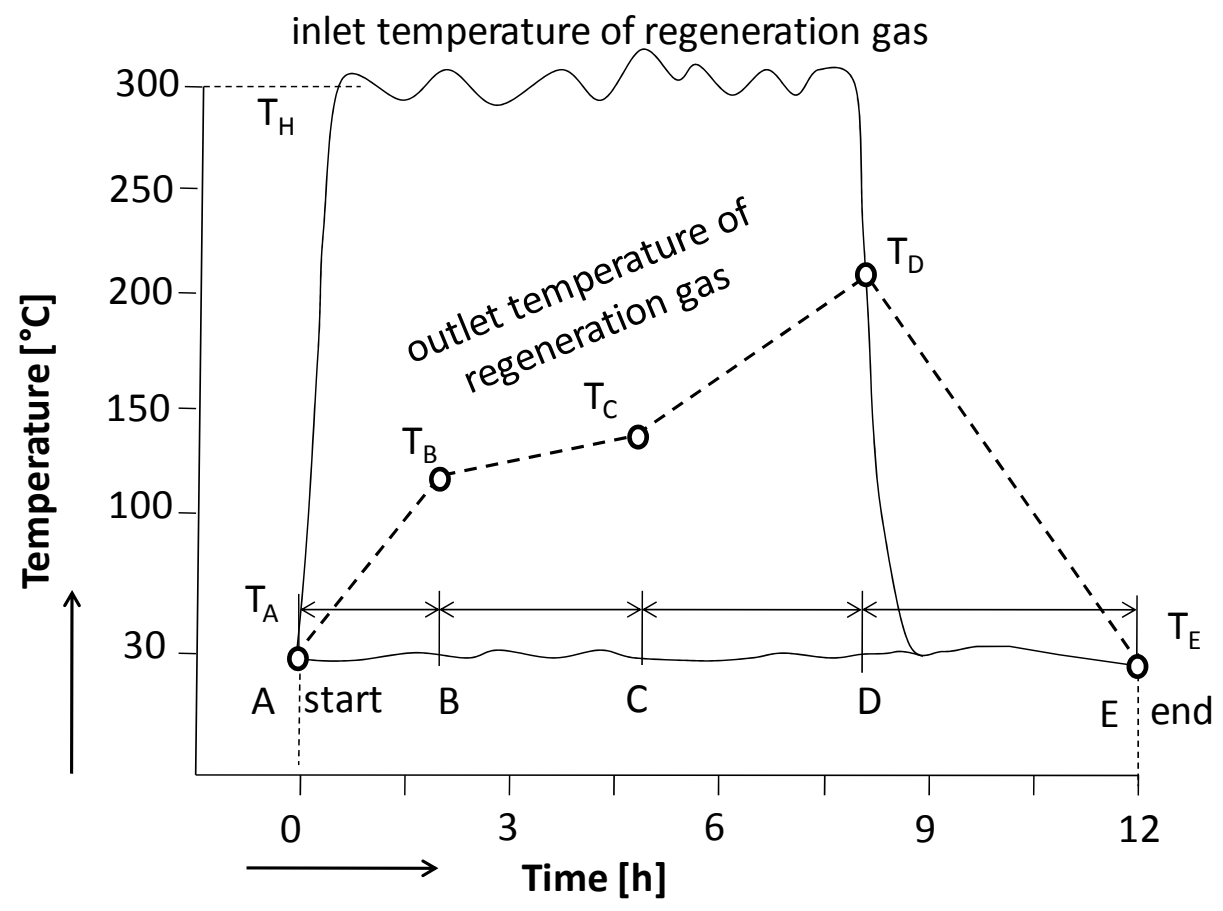

Figure 5. Typical temperature course for $12 \mathrm{~h}$ TSA regeneration of molecular sieves 
The shape of the curve representing the course of the outlet regeneration gas temperature is typically composed of four regions. They are specified by time borders A, B, C and D with appropriate border temperatures $\mathrm{T}_{\mathrm{A}}, \mathrm{T}_{\mathrm{B}}, \mathrm{T}_{\mathrm{C}}$ and $\mathrm{T}_{\mathrm{D}}$. Regeneration starts at point $\mathrm{A}$. The inlet regeneration gas warms the column and the adsorbent. At a temperature around $120^{\circ} \mathrm{C}\left(\mathrm{T}_{\mathrm{B}}\right)$ the sorbed humidity starts to evaporate from the pores. The adsorbent continues warming more slowly, because a considerable part of the heat is consumed by water evaporation. From point $\mathrm{C}$, it can be assumed that all water has been desorbed. The adsorbent is further heated to desorb $\mathrm{C}_{5+}$ and other contaminants. The regeneration is completed when the outlet temperature of the regeneration gas reaches $180-190^{\circ} \mathrm{C}(\mathrm{TD})$. Finally, cooling proceeds from point $\mathrm{D}$ to point $\mathrm{E}$. The temperature of the cooling gas should not decrease below $50^{\circ} \mathrm{C}$, in order to prevent any water condensation from the cooling gas [13].

Part of the dehydrated NG is usually used as the regeneration gas. After regenerating the adsorbent the regeneration gas is cooled, and the water condensed from it is separated. After water separation, the regeneration gas is added back to the inlet stream or alternatively to the dehydrated stream.

The total energy used for regeneration is composed of heat to warm the load (30\%), heat for desorption (50\%) and heat going into the structure (20\%). With proper internal insulation of the adsorption towers, the heat going to the structure can be minimized and around $20 \%$ of the invested energy can be saved.

So-called LBTSA (Layered Bed Temperature-Swing Adsorption) processes are an upgrade of the TSA method. Here, the adsorption column is composed of several layers of different adsorbents. Hence the properties of the separate adsorbents are combined in a single column. For example, in NG dehydration a combination of activated alumina with molecular sieve $4 \mathrm{~A}$ is used. Alumina has better resistance to liquid water, so a thin layer is put in first place to contact the wet NG. This ordering supports the lifetime of the molecular sieve, which is placed below the alumina layer. The effect of adsorbent lifetime extension is shown for two cases in Figure 6. It can be seen that contact with liquid water dramatically decreases the lifetime of the molecular sieve [14].

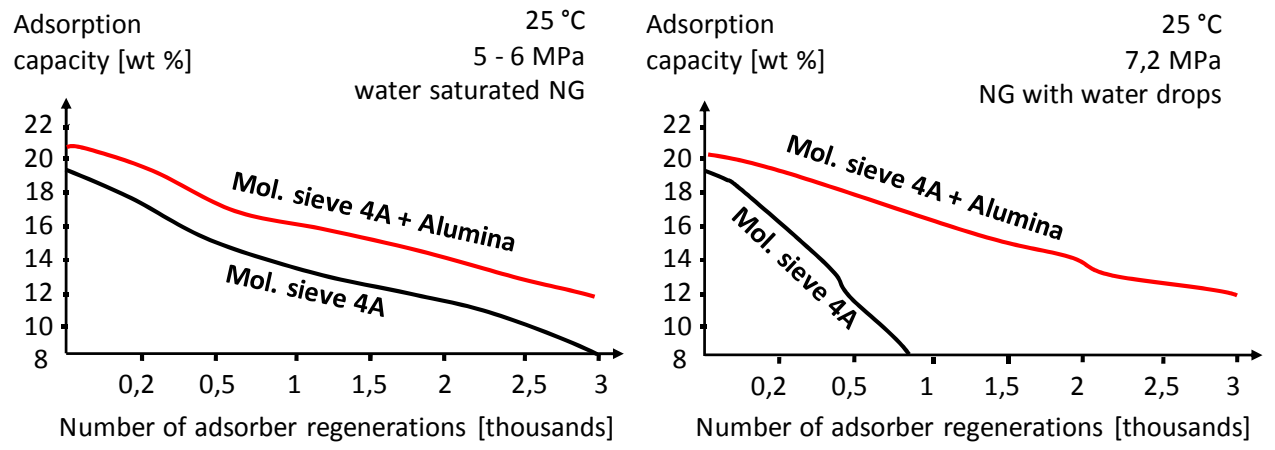

Figure 6. Effect of layered bed adsorption on the lifetime of the adsorbent 


\subsection{Condensation}

The third conventional dehydration method employs gas cooling to turn water molecules into the liquid phase and then removes them from the stream. Natural gas liquids and condensed higher hydrocarbons can also be recovered from NG by cooling. The condensation method is therefore usually applied for simultaneous dehydration and recovery of natural gas liquids.

NG can be advantageously cooled using the Joule-Thompson effect (JT effect). The JT effect describes how the temperature of a gas changes with pressure adjustment. For NG, thanks to expansion, the average distance between its molecules increases, leading to an increase in their potential energy (Van der Waals forces). During expansion, there is no heat exchange with the environment, and no work creation. Therefore, due to the conservation law, the increase in potential energy leads to a decrease in kinetic energy and thus a temperature decrease of NG. However, there is another phenomenon connected with the cooling of wet NG. Attention should be paid to the formation of methane hydrate. Hydrates formed by cooling may plug the flow. This is usually prevented by injecting methanol or monoethylenglycol (MEG) hydrate inhibitors before each cooling. Figure 7 depicts an industrial application of dehydration method utilizing the JT effect and MEG hydrate inhibition.

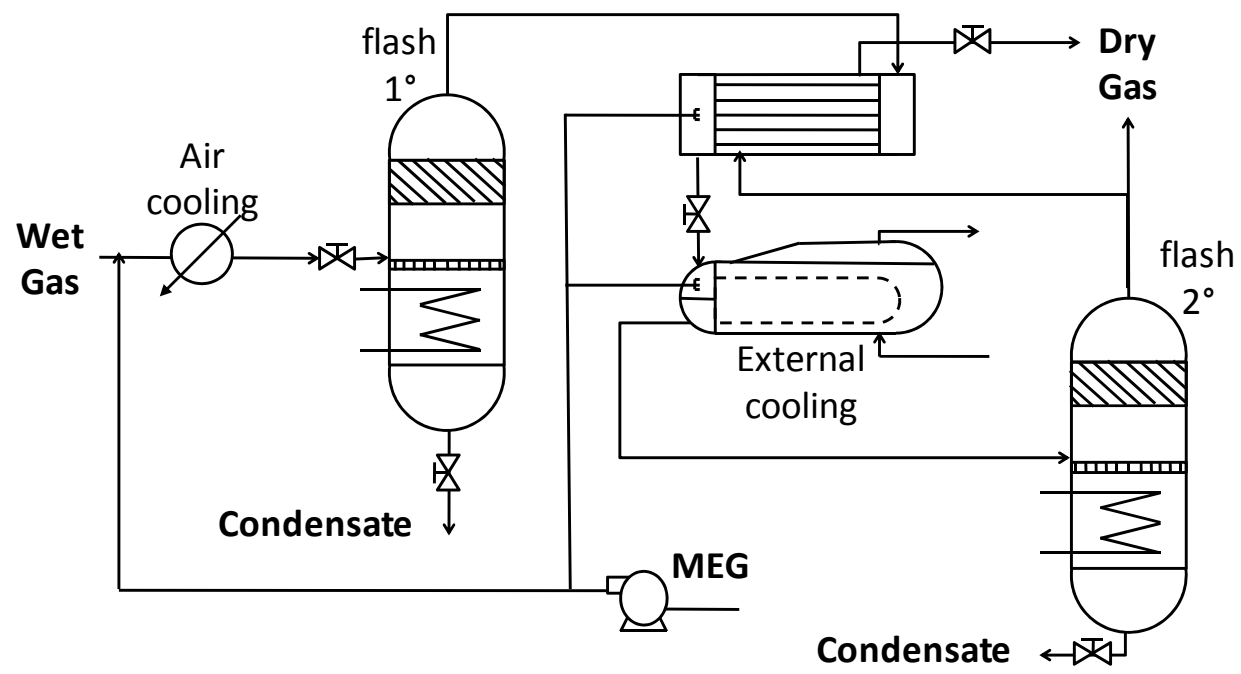

Figure 7. Dehydration method utilizing the JT effect and hydrate inhibition

The wet NG is throttled in two steps inside the flash tanks. The lower temperature (due to the JT effect) of the gas stream in the flash tanks leads to partial condensation of the water vapors. The droplets that are created are removed from the gas stream by a demister inside the flashes. In cases where cooling by the JT effect is insufficient (the usable pressure difference between the inlet and outlet of the gas is insufficient), the air pre-cooler and the 
external cooler are turned on. Since dehydration is normally applied to large volumes of NG, the external coolers need to have high performance, so this type of cooling is very energy expensive. For dehydration of low pressures NG the external coolers consumes up to $80 \%$ of total energy of dehydration unit. However, if the usable pressure difference is high, the JT effect inside the flashes is so strong that internal heating of the flashes is required to defreeze any methane hydrate or ice that may form. A condensation method is applied when suitable conditions for the JT effect are available.

\subsection{Supersonic separation}

The principle of this method lies in the use of the Laval Nozzle, in which the potential energy (pressure and temperature) transforms into kinetic energy (velocity) of the gas. The velocity of the gas reaches supersonic values. Thanks to gas acceleration, sufficient temperature drops are obtained. Tdew of water vapor in NG is reached, and nucleation of the droplets proceeds. Figure 8 depicts the basic design of a supersonic nozzle [15].

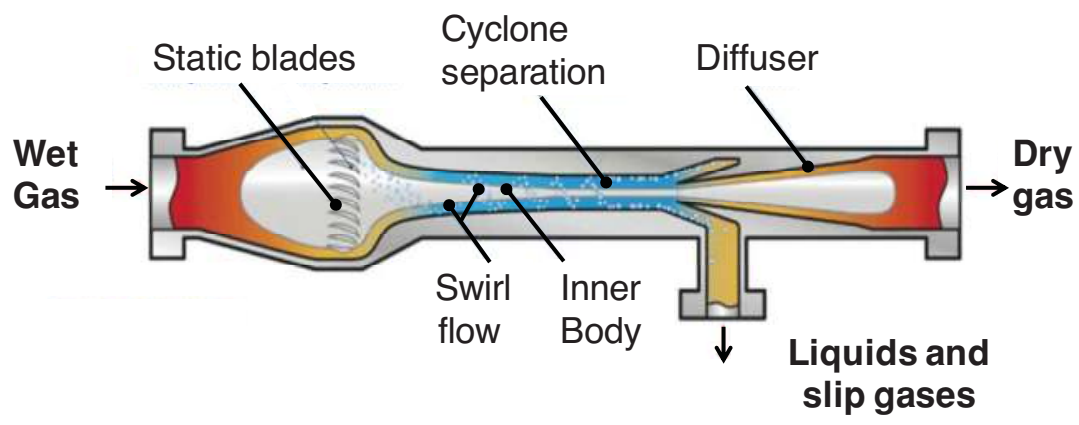

Figure 8. Design of a supersonic nozzle for NG dehydration

At the inlet to the nozzle there are static blades which induce a swirling flow of the gas. The water droplets that form are separated by the centrifugal force on the walls. The centrifugal force in the supersonic part of the nozzle can reach values up to $500000 \mathrm{~g}$ [16]. The thin water film on the walls moves in the direction of flow into the separation channel. The separation channel leads into the heated degas separator. From here, the slip gas is returned back to the main stream and the water condensate is removed. After separation of the water it is important to recover the pressure of the gas from its kinetic energy. A shock wave is used to achieve this. Generally, shock waves form when the speed of a gas changes by more than the speed of sound. In supersonic nozzles, the shock wave is created by rapid enlargement of the nozzle diameter. This part of the nozzle is called the diffuser. Thanks to the diffuser $65-80 \%$ of the inlet pressure is recovered [17]. This section might also include another set of static devices to undo the swirling motion. The profile of pressure, temperature and velocity of a gas passing through the supersonic nozzle is depicted below. 


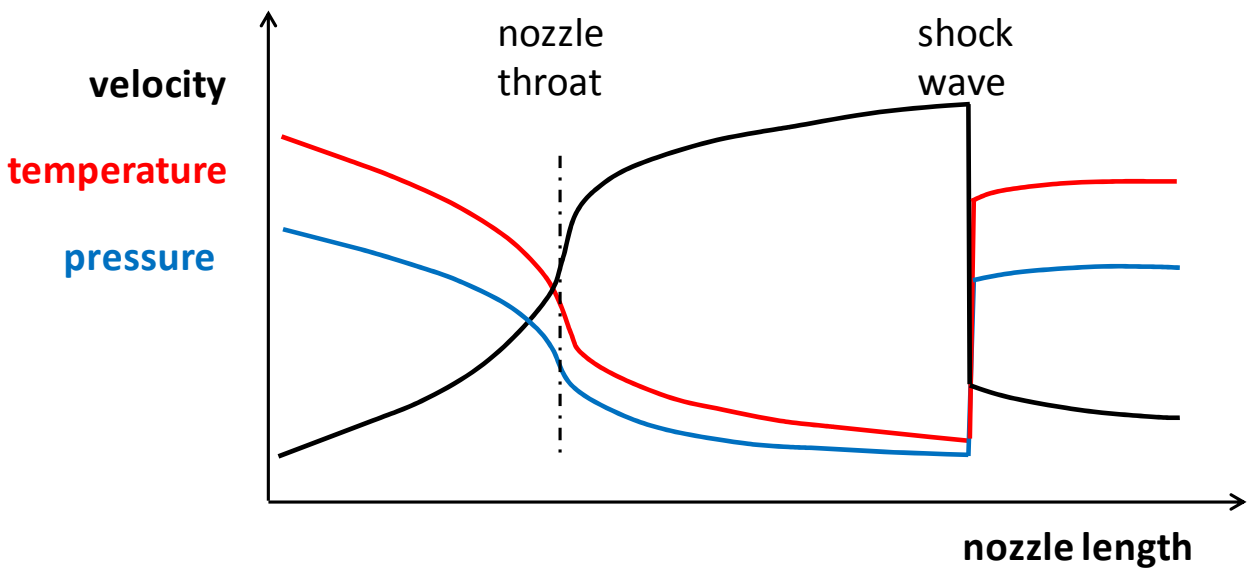

Figure 9. Profile of pressure, temperature and velocity of a gas passing through the supersonic nozzle

The scheme of a supersonic dehydration line working on the principle introduced here is depicted in Figure 10.

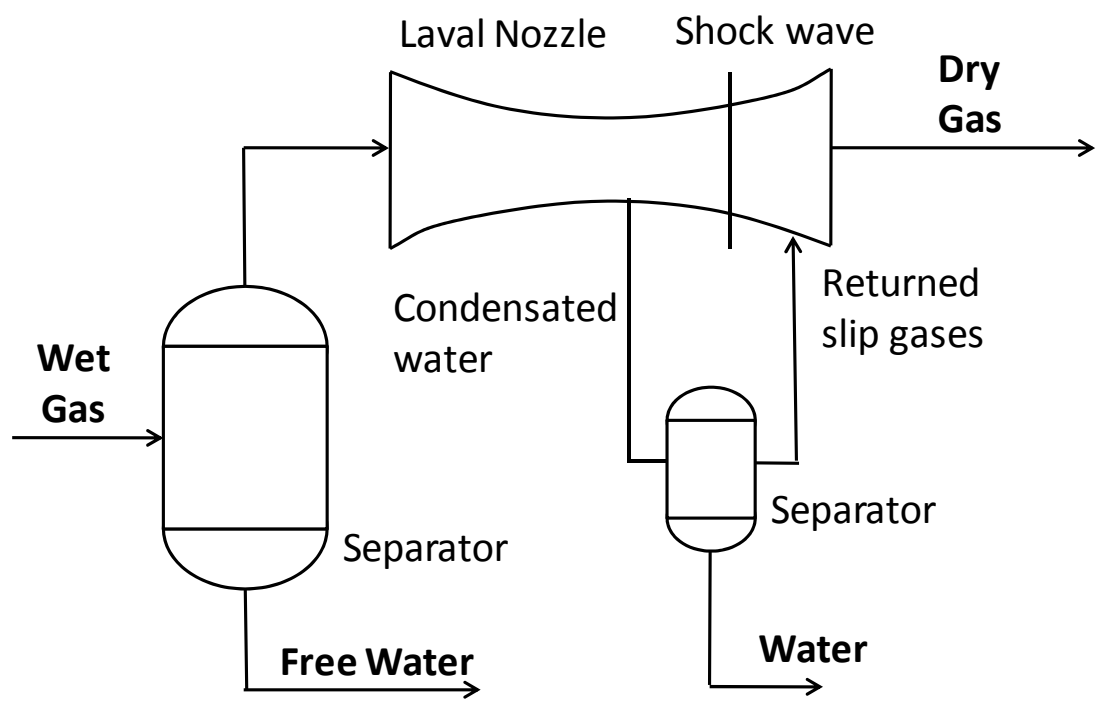

Figure 10. Scheme of a supersonic dehydration line

The gas residence time in the supersonic nozzle is below two milliseconds [18]. This time interval is too short for any methane hydrate formation, so no inhibitors are needed. To obtain supersonic velocity of the gas, the inlet diameter should be minimally $\sqrt{5}$ times higher than the nozzle throat. The geometry of the tapered section of the Laval nozzle is calculated by the following equations [16] 


$$
\begin{array}{lll}
\frac{D-D_{c r}}{D_{1}-D_{c r}}=1-\frac{1}{X_{m}^{2}}\left(\frac{x}{L}\right)^{3} & & \left(\frac{x}{L} \leq X_{m}\right) \\
\frac{D-D_{c r}}{D_{1}-D_{c r}}=\frac{1}{\left(1-X_{m}\right)^{2}}\left(1-\frac{x}{L}\right)^{3} & & \left(\frac{x}{L}>X_{m}\right)
\end{array}
$$

Where $\mathrm{D}_{1}, \mathrm{D}_{\mathrm{cr}}, \mathrm{L}, \mathrm{X}_{\mathrm{m}}$ stand for the inlet diameter, the throat diameter, the length of the tapered section, and the relative coordinate of tapered curve, respectively; $x$ is the distance between an arbitrary cross section and the inlet, and $\mathrm{D}$ is the convergent diameter at an arbitrary cross section of $\mathrm{x}$.

A model of a supersonic dehydration unit was analyzed with the use of numerical simulation tools, and the separation efficiency in respect to lost pressure was evaluated. The simulations were performed on water saturated $\mathrm{NG}$ at $30 \mathrm{MPa}$ and $20^{\circ} \mathrm{C}$. The results are presented in Table 4 [19].

\begin{tabular}{|l|l|l|l|l|l|}
\hline Pressure lost in nozzle (\%) & 17,3 & 20,0 & 27,6 & 49,0 & 51,5 \\
\hline Water separation efficiency (\%) & 40 & 50 & 90 & 94 & 96 \\
\hline
\end{tabular}

Table 4. Supersonic water separation efficiency in respect to pressure lost in the nozzle

The supersonic separation is a promising new technology. The main advantage of the method is the small size of the supersonic nozzle. For example, a nozzle $1,8 \mathrm{~m}$ in length placed in a housing $0,22 \mathrm{~m}$ in diameter was used for dehydrating $42000 \mathrm{~ms}^{3}$ per hour of water-saturated NG at $25^{\circ} \mathrm{C}$ compressed to $10 \mathrm{MPa}$ to output water $\mathrm{T}_{\mathrm{dew}}<-7^{\circ} \mathrm{C}$ [20]. The corresponding absorption contactor would be $5 \mathrm{~m}$ in height and 1,4 $\mathrm{m}$ in diameter, and the corresponding adsorption line would be composed of two adsorbers $3 \mathrm{~m}$ in height and $1 \mathrm{~m}$ in diameter. A further advantage is the simplicity of the supersonic dehydration unit. The supersonic nozzle contains no moving parts and requires no maintenance. The operating costs are much lower than for other methods. The only energy-consuming devices are the pumps for removing the condensate and the heater for the degas separator. However, during supersonic dehydration a pressure loss occurs. However, if the same pressure loss were used for the JT effect, the temperature drop would be 1,5 - 2,5 times lower [21]. Supersonic separation enables simultaneous removal of water and higher hydrocarbons from the treated gas, and can be used as pretreatment method before NG liquefaction. This method could also be usable for other applications of gas separation.

The application of supersonic separation has some disadvantages. The most limiting condition of use is the need for stationary process parameters. Fluctuations in temperature, pressure or flow rate influence the separation efficiency. However, it is in many cases impossible to achieve constant process parameters. For example, this is the case when withdrawing NG from UGS. However, supersonic dehydration can be used even in this case. The problem is solved by arranging several nozzles into a battery configuration with a single common degas separator. The battery configuration enables an optimal number of nozzles to be switched on, depending on the inlet parameters of the gas. The scheme of a possible arrangement is depicted in Figure 11 below [22]. 


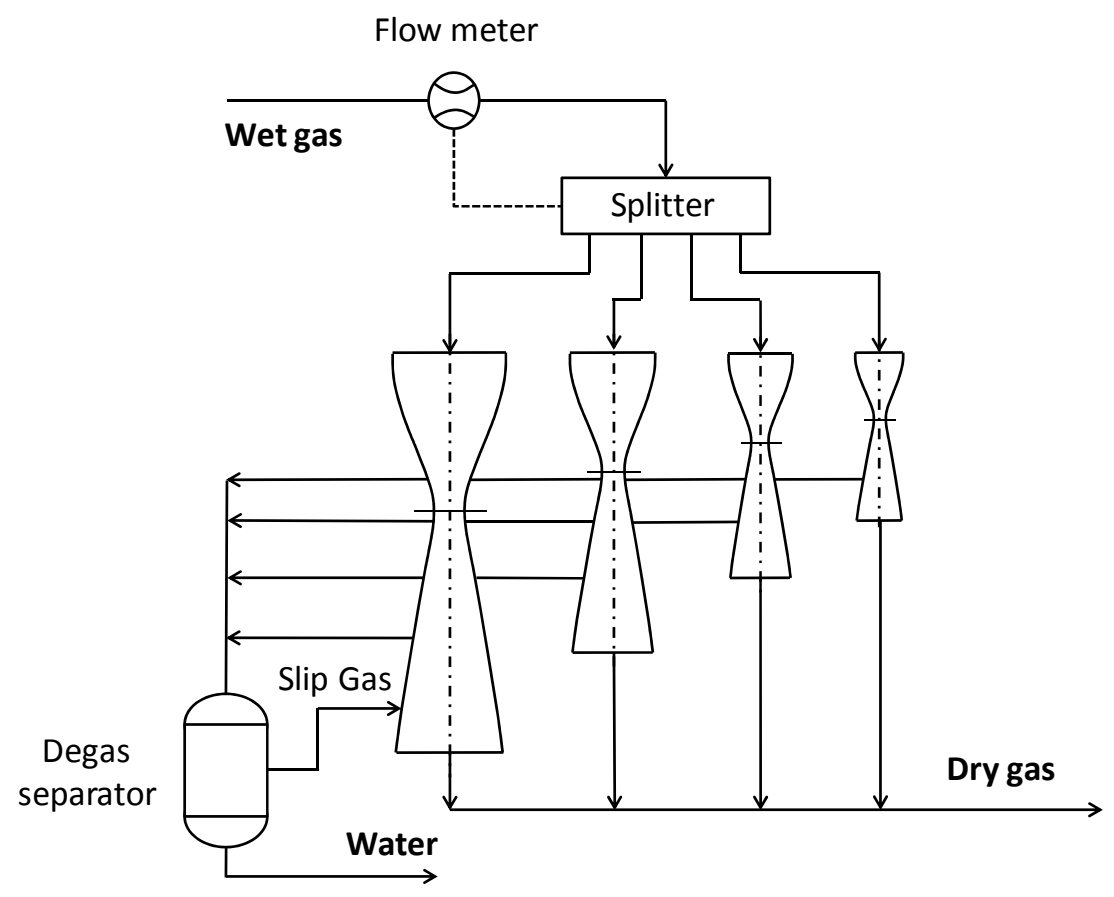

Figure 11. Arrangement of supersonic nozzles for unsteady inlet parameters of NG

Nozzle A is designed to process $80 \%$ of the nominal gas flow. Nozzles B, C, D are in the proportion 4:2:1 with respect to the processed gas flow. Nozzles B, C, D together can process $40 \%$ of the nominal gas flow. This arrangement therefore enables $\pm 20 \%$ deviation of the nominal flow to be covered. With appropriate switching of the nozzles, the maximal deviation between the real gas flow and the designed flow for the combination of nozzles is below $4 \%$.

A further disadvantage of the supersonic dehydration is its novelty. The appropriate nozzle design is complicated, and "know how" is expensive. The geometry of the nozzle ranges in the order of micrometers. In addition, the construction material has to withstand abrasion and the impacts of a shock wave.

\section{Comparison of conventional dehydration methods}

\subsection{General comparison}

Each of the methods presented here has its advantages and disadvantages. Absorption by TEG is nowadays the most widely used method. Outlet $\mathrm{T}_{\text {dew }}$ around $-10^{\circ} \mathrm{C}$ is usually reached and this water concentration is sufficient for pipeline distribution of NG. Indeed, with improved reboiler design (Vacuum Stripping, Drizo, Coldfinger), the outlet $T_{\text {dew }}$ is even 2 - 3 times lower. However TEG has a problem with sulfur, and with gas contaminated with 
higher hydrocarbons. The TEG in the reboiler foams, and with time it degrades into a "black mud". BTEX emissions (the acronym stands for benzene, toluene, ethylbenzene and xylenes) in the flash gases and in the reboiler vent are a further disadvantage.

Adsorption dehydration can achieve very low outlet water concentration $\mathrm{T}_{\mathrm{dew}}<-50^{\circ} \mathrm{C}$, and contaminated gases are not a problem. Even corrosion of the equipment proceeds at a slower rate. However, adsorption requires high capital investment and has high space requirements. The adsorption process runs with at least two columns (some lines use three, four, or as many as six). Industrial experience indicates that the capital cost for an adsorption line is 2 - 3 times higher than when absorption is used [5]. In addition, the operating costs are higher for adsorption than for absorption.

Expansion dehydration is the most suitable method in cases where a high pressure difference is available between UGS and the distribution connection. However, the difference decreases during the withdrawal period and becomes insufficient, so that an external cooling cycle is needed. A cycle for regenerating hydrate inhibitor from the condensate separated inside the flashes is also required.

The general overview of areas suitable for application of target dehydration method is depicted on the following Figure 12.

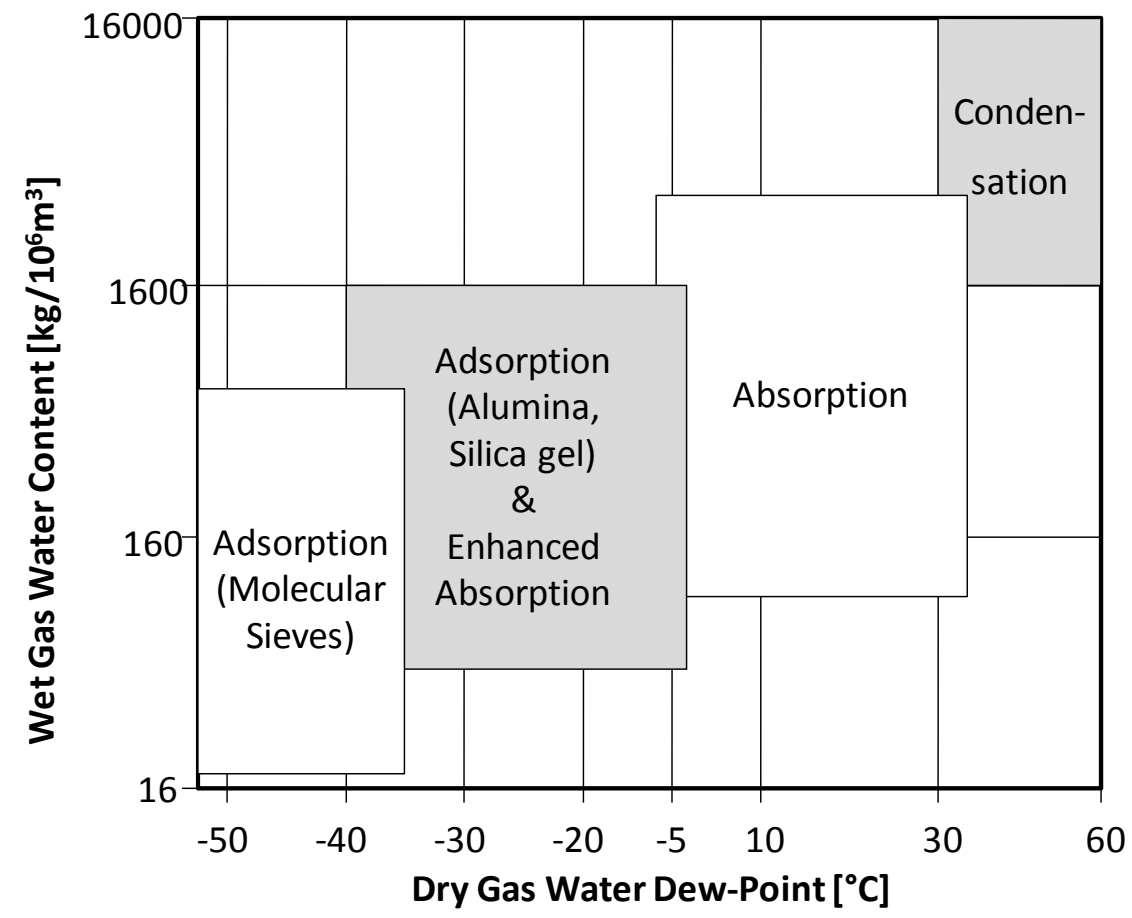

Figure 12. Overview of areas suitable for application of target dehydration method 


\subsection{Energy comparison based on own analyses and available data}

The energy demand of the conventional methods presented here is compared on the basis of a model, where a volume of $10^{5} \mathrm{~ms}^{3} / \mathrm{h}$ of NG from UGS is processed. The NG is water saturated at a temperature of $30^{\circ} \mathrm{C}$. The pressure of the gas is varied from 7 to $20 \mathrm{MPa}$, but in the case of the condensation method the pressure range starts at $10 \mathrm{MPa}$. The required outlet water concentration of in NG is equivalent to dew point temperature $-10^{\circ} \mathrm{C}$ at gas pressure 4 $\mathrm{MPa}$ [23].

The calculation of TEG absorption is based on GPSA (2004) [24]. The results are compared with the paper by Gandhidasan (2003) [5] and with industrial data provided by ATEKO a.s. The total energy demand is composed of heat for TEG regeneration in the reboiler, energy for the pumps, filtration and after-cooling the lean TEG before entering the contactor. Enhanced regeneration is not considered. The basic parameters for the calculation are: regeneration temperature $200^{\circ} \mathrm{C}$, concentration of lean TEG $98,5 \mathrm{wt} . \%$, and circulation ratio 35 lTEG/kgH2O [24].

For calculating adsorption dehydration, molecular sieve $5 \mathrm{~A}$ is considered to be the most suitable adsorbent. The total energy demand is directly connected to the regeneration gas heater, and no other consumption is assumed. The calculations are again based on GPSA (2004) [24]. The results are compared with the paper by Gandhidasan (2001) [4] and also with the publication by Kumar (1987) [7]. The calculation procedure for GPSA and Gandhidasan arises from the summation of the particular heats, i.e. the heat for adsorbent warming, the heat for column warming (insulation of the adsorption towers is considered), and the heat for water desorption. Kumar's calculation procedure runs differently. The regeneration step is divided into four regions (as depicted in Figure 5). Afterwards, we determine what individual phenomena proceed in each region, what the border and average temperatures are, and how much energy is required to cover these phenomena. Finally, the demands for each region are added. The basic parameters for all procedures are: temperature of the regeneration gas $300^{\circ} \mathrm{C}$, time of adsorption/regeneration $12 \mathrm{~h}$, and two column designs.

The condensation method was calculated on the basis of industrial data provided by TEBODIN s.r.o. and supplementary calculations of the JT effect. The key parameter influencing energy demand is the pressure of NG. Because it is not feasible to apply this method for low pressures, and because the provided data starts at $10 \mathrm{MPa}$, the pressure range was adjusted. The total energy demand consists of the air pre-cooling unit, the external cooling, the pumps for MEG injection and condensate off take, the heat for MEG regeneration, and flash heating.

\subsection{Results of the analyses}

The results obtained for the TEG absorption method are the same for each of the calculation procedures, and good agreement with industrial data was also obtained. However, the calculation procedures for the adsorption method lead to different results. Hence the 
average energy demand value was taken as the reference. The maximum deviation from it is below $20 \%$ for all calculation procedures. The source of the deviation lies in the "loss factor and the non-steady state factor". In the case of the condensation method, the calculated values for the JT effect were in good agreement with the industrial data, but the amount of data was limited, resulting in limited representation of the condensation method.

The final energy consumption results for each dehydration method are summarized by the graph in Figure 13.

For low pressures (pressure of NG from UGS $<13 \mathrm{MPa}$ ), the condensation method is the most demanding. Its demand decreases linearly with pressure to a value of $145 \mathrm{~kW}$ for 13 $\mathrm{MPa}$. At this point, the energy demand for the condensation method is roughly the same as for the adsorption method. When the NG pressure is further increased from $13 \mathrm{MPa}$ to 16 $\mathrm{MPa}$, the energy demand for the condensation method still decreases, but with a lowering tendency. For a high pressure of NG (> 16 MPa), the energy demand of the condensation method is at its lowest, and it remains nearly constant, with an average value around $36 \mathrm{~kW}$.

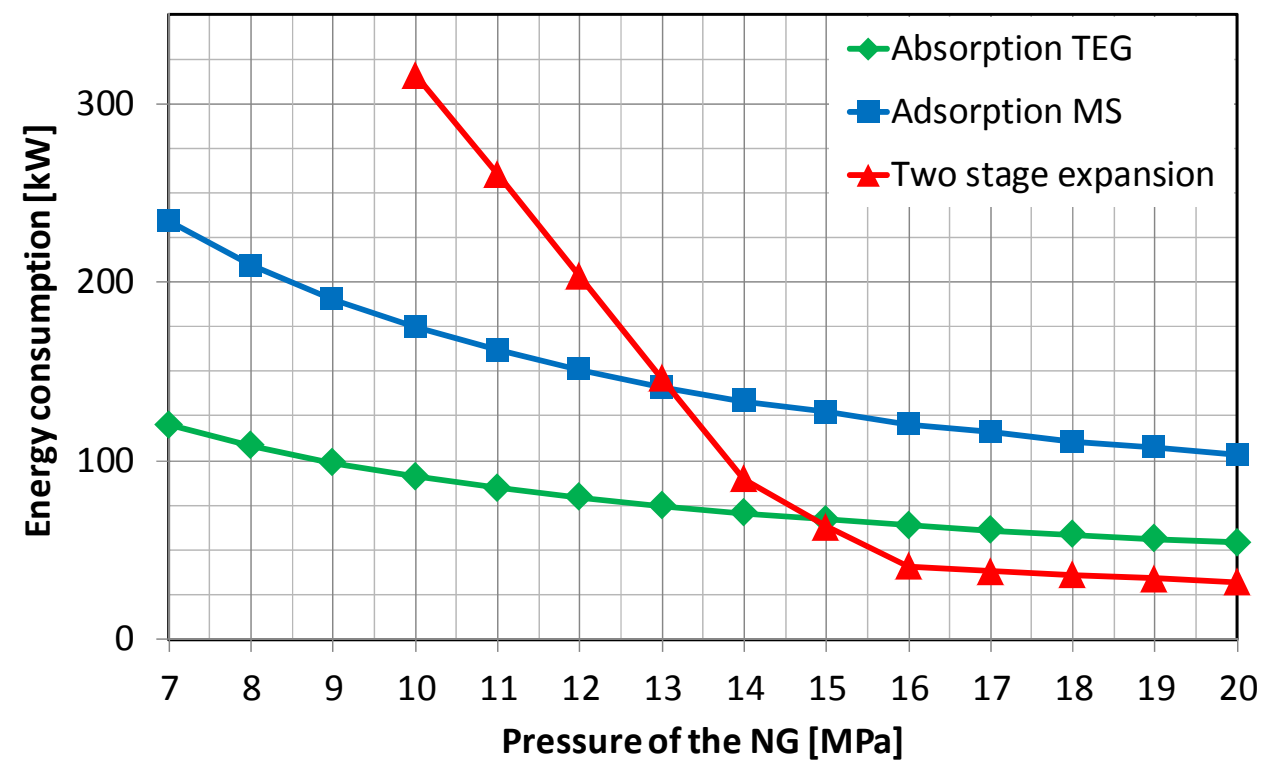

Figure 13. Energy consumption results for conventional dehydration methods

The course of the energy demand for the adsorption and absorption methods is quite similar: with increasing pressure of dehydrated NG the energy demand slowly decreases. The absorption method is less demanding on the whole pressure scale, and begins with consumption of $120 \mathrm{~kW}$ at $7 \mathrm{MPa}$. The adsorption method starts with $234 \mathrm{~kW}$ at $7 \mathrm{MPa}$, but the energy demand decreases slightly more as the pressure of NG in UGS rises. This leads to a gradual decrease in the difference between these methods, and the energy demand at the final pressure value of $20 \mathrm{MPa}$ is equal to $54 \mathrm{~kW}$ for absorption and $103 \mathrm{~kW}$ for adsorption. 


\subsection{Conclusions of the analyses}

By far the highest energy demand of the condensation method at low pressures of NG from UGS is due to the pressure being close to the distribution pressure, so that pressure cannot be used for the JT effect in flashes. Cooling is then compensated by the air pre-cooler and the external cooling device, which are unsuitable for large volumes of processed NG. However, as the pressure difference between UGS and the distribution site increases, the space for expansion rises and the JT effect proceeds with increasing impact. This is projected into a linear decrease in the energy demand of the air pre-cooler and the external cooling device. From the point where there is a pressure of $\mathrm{NG}>14 \mathrm{MPa}$, flash heating is gradually turned on to prevent any freezing caused by the strong JT effect. The energy demand of flash heating is reflected in the total energy consumption. Finally, for pressures of NG $>16 \mathrm{MPa}$, total cooling and subsequent condensation is achieved by the JT effect. The total energy demand remains constant, and consists of flash heating and inhibitor injection and regeneration.

In case of the adsorption and absorption dehydration method, the similar falling course of the energy demand with increasing pressure of NG can be explained by the fact that with increasing pressure within a UDG the amount of water present in the NG decreases. The absorption method generally consumes less energy, because the regeneration of TEG is less demanding than adsorbent regeneration. The composition of the total energy demand of the adsorption method can be divided into three parts. The heat for water desorption is approximately $55 \%$, for warming the adsorbent it is $31 \%$, and for warming the column it is $14 \%$. It also has to be assumed that just part of the heat in the regeneration gas transfers to the adsorbent, the column and heat loss leaves to the atmosphere, and the balance leaves with the hot gas.

In brief, in cases of high pressure the most appropriate dehydration method from the energy demand point of view is the stored NG condensation method. This holds for NG from UGS with pressure $>15 \mathrm{MPa}$ and distribution pressure requirements $7 \mathrm{MPa}$. For lower pressures, the condensation method is used if the objective is to recover NGL and remove water simultaneously. However, this is usually not the case when storing NG in a UGS. In cases where insufficient pressure difference is available, the absorption method is therefore favored over the adsorption method in terms of energy demand. TEG absorption is almost twice less demanding. However, if a gas contaminated with sulfur or higher hydrocarbons is being processed, the TEG in the reboiler foams and degrades with time. This can occur when a depleted oil field is used as a UGS. Adsorption is preferred in cases where very low $\mathrm{T}_{\mathrm{dew}}$ (water concentration lower than 1 ppm can be achieved) of NG is required, for example when NG is liquefied.

It is worth to note that the power comparison can be used as a measure of the technical excellence. From power data the specific energy consumption was calculated and its values indicate that the energy cost is much lower than the investment cost (depreciations). On the other hand the energy cost represents more than $60 \%$ of the total operating cost.

\section{Conclusions and recommendations}

The chapter should help in the selection of a proper dehydration method and in calculating NG dehydration. The following methods are available as options: absorption, adsorption 
and condensation. Absorption is used in cases when emphasis is not placed on the water content of the output stream, and when low operating and capital investment are required. Adsorption is used in cases when bone dry NG is required. Low temperature separation employing the JT effect is used in cases where a sufficient pressure drop is available between the input and the output of the dehydration unit. Supersonic nozzles are a promising method that will in future displace these three conventional methods.

We have selected for citation here articles and procedures that we consider to provide reliable results.

\title{
Author details
}

Michal Netušil and Pavel Ditl

Czech Technical University in Prague, Faculty of Mechanical Engineering, Department of Process

Engineering, Prague, Czech Republic

\section{Acknowledgement}

The authors are grateful for the financial support provided by Ministry of Industry and Trade of the Czech Republic (program TIP nr. FR-TI1/173).

\author{
Abbreviations \\ NG - natural gas \\ UGS - underground gas storage \\ lbs - pounds \\ MMcft - millions of cubic feet \\ TEG - triethyleneglycol \\ MEG - monoethylenglycol \\ TSA - temperature swing adsorption \\ LBTSA - layered bed temperature swing adsorption \\ JT effect - Joule-Thompson effect \\ BTEX - benzene, toluene, ethylbenzene and xylenes
}

\section{Symbols}

$T_{\text {dew }}$ - dew point temperature

gH2O - grams of water

$\mathrm{ms}^{3}$ - standard cubic meters of gas $(293,15 \mathrm{~K} ; 101,325 \mathrm{kPa})$

Wwater - kilograms of water per $10^{6} \mathrm{~ms}^{3}$ of NG

$\mathrm{t}_{\mathrm{G}}$ - temperature of $\mathrm{NG}$ in ${ }^{\circ} \mathrm{C}$

$\mathrm{C}_{5+}$ - pentane and higher hydrocarbons

$\mathrm{PG}_{\mathrm{G}}$ - pressure of $\mathrm{NG}$ in $\mathrm{MPa}$

Q - density of NG in $\mathrm{kg} / \mathrm{m}^{3}$

$\gamma$ - activity coefficient dimensionless 
CTEG - weight concentration of TEG in TEG/water solution

lTEG - liters of TEG

kgH2O - kilograms of water

$\mathrm{D}_{1}$ - inlet diameter of nozzle $\mathrm{mm}$

$D_{\text {cr }}$ - throat diameter of nozzle mm

$\mathrm{L}$ - length of tapered section of nozzle in $\mathrm{mm}$

$\mathrm{X}_{\mathrm{m}}$ - relative coordinate of tapered curve in $\mathrm{mm}$

$\mathrm{D}$ - convergent diameter in $\mathrm{mm}$

$\mathrm{x}$ - distance between arbitrary cross section and the inlet in $\mathrm{mm}$

g - standard gravity

\section{References}

[1] Gas infrastructure Europe (2011) Map Dataset in Excel-format Storage map. Available: http://www.gie.eu/maps_data/storage.html. Accessed 2011 Mar 8.

[2] Foss M (2004) Interstate Natural Gas Quality Specifications and Interchangeability. Center for Energy Economics.

[3] NET4GAS (2011) Gas quality parameters. Available at: http://extranet.transgas.cz/caloricity_spec.aspx. Accessed 2011 Mar 8.

[4] Gandhidasan P, Al-Farayedhi A, Al-Mubarak A (2001) Dehydration of natural gas using solid desiccants. Energy 26: 855-868.

[5] Gandhidasan P (2003) Parametric Analysis of Natural Gas Dehydration by Triethylene Glycol Solution. Energy Sources 25: 189-201.

[6] CHEM Group, Inc. (2012) Triethylene Glycol - Liquid Density Data. Available at: http://www.chem-group.com/services/teg-density.tpl. Accesed 2012 Mar 6.

[7] CHEM Group, Inc. (2012) Triethylene Glycol - Kinematic Viscosity Data. Available at: http://www.chem-group.com/services/teg-viscosity.tpl. Accesed 2012 Mar 6.

[8] Bahadori A, Vuthaluru H.B (2009) Simple methodology for sizing of absorbers for TEG gas dehydration systems. Energy 34: 1910-1916

[9] Hubbard R.A, Campbell J.M (2000) An appraisal of gas dehydration processes. Hydrocarbon Engineering 5: 71-74.

[10] Tagliabue M, Farrusseng D, Valencia S, Aguado S, Ravon U, Rizzo C (2009) Natural gas treating by selective adsorption: Material science and chemical engineering interplay. Chemical Engineering Journal 155: 553-566

[11] Roušar I, Ditl P (1993) Pressure swing adsorption: analytical solution for optimum purge Original Research, Chemical Engineering Science 48: 723-734.

[12] Roušar I, Ditl P, Cekal M (1993) Pressure swing adsorption - the optimization of multiple bed units, Precision Process Technology: perspectives for pollution prevention: 483-492.

[13] Kumar S (1987) Gas Production Engineering. Houston: Gulf Professional Publishing 239 p.

[14] Jochem G (2002) Axens Multibed Systems for the Dehydration of Natural Gas, PETEM. 
[15] Schinkelshoek P, Epsom H.D (2008) Supersonic gas conditioning - commercialization of twister technology. 87th Annual Convention. Grapevine, Texas.

[16] Wen C, Cao X, Zhang J, Wu L (2010) Three-dimensional Numerical Simulation of the Supersonic Swirling Separator. Twentieth International Offshore and Polar Engineering Conference. Beijing, China.

[17] Okimoto F, Brouwer J.M (2002) Supersonic gas conditioning, World Oil 34: 89-91

[18] Ma Q, Hu D, Jiang J, Qiu Z (2010) Numerical study of the spontaneous nucleation of self-rotational moist gas in a converging-diverging nozzle. International Journal of Computational Fluid Dynamics: 29-36.

[19] Karimi A, Abdi M.A (2006) Selective dehydration of high-pressure natural gas using supersonic nozzles, Chemical Engineering and Processing 48: 560-568

[20] Twister BV (2012) Twister supersonic separator - Experience. Available: http://twisterbv.com/products-services/twister-supersonic-separator/experience/. Accesed 2012 Mar 7.

[21] Betting M, Epsom H (2007) High velocities make a unique separator and dewpointer, World Oil, 197-200.

[22] Netušil M, Ditl P, González T (2012) Raw gas dehydration on supersonic swirling separator, 19th International Conference Process Engineering and Chemical Plant Design, Krakow.

[23] Netusil M, Ditl P (2011) Comparison of three methods for natural gas dehydration, Journal of Natural Gas Chemistry 20: 471 - 476

[24] GPSA (2004) Engineering Data Book. 12th ed. Tulsa: GPSA Press. 